\title{
Determination of Arginine and Ascorbic acid in effervescent tablers by multidimensional chromatography
}

\author{
Andrea E. Rech ${ }^{\mathrm{a}}$; Cristina P. Farina ${ }^{\mathrm{b}}$, Pamela C. Lukasewicz Ferreira ${ }^{\mathrm{c}}$ \\ and Diogo Miron ${ }^{\mathrm{ad}^{*}}$ \\ a School of Pharmacy, Health Science, Caxias do Sul University- UCS, Rua Francisco Getúlio Vargas, 1130. CEP \\ 95070-560 - Caxias do Sul-RS, Brasil \\ ${ }^{b}$ Laboratório Farmacêutico Vitamed, Caxias do Sul, Rua Flávio Francisco Bellini, 459. \\ CEP 95098-170 - Caxias do Sul - RS, Brasil. \\ ${ }^{c}$ Postgraduate Program in Pharmaceutical Sciences, School of Pharmacy, Federal University of Rio Grande do Sul. Av. \\ Ipiranga, 2752 - Lab. 703. CEP 90610-000 - Porto Alegre-RS, Brasil. \\ ${ }^{d}$ School of Pharmacy, Federal University of Rio Grande do Sul. \\ Corresponding author e-mail: diogomiron@hotmail.com \\ This paper describes a fast and direct method for quantification of arginine and ascorbic acid (vitamin C) in effervescent \\ tablets. HPLC-UV multidimensional chromatography (RP18 and cyanopropyl columns) was developed and validated. \\ Phosphate buffer $10 \mathrm{mM} \mathrm{pH} 3.4$ was used as mobile phase. Satisfactory resolution between the drugs was obtained with \\ analysis time less than $8.0 \mathrm{~min}$. Method was linear in the ranges of $140-320 \mu \mathrm{g} . \mathrm{mL}^{-1}$ and $240-560 \mu \mathrm{g} \cdot \mathrm{mL}^{-1}$ for arginine and \\ ascorbic acid, respectively. Precision showed RSD <2.0\%. Recovery was $99.5 \%$ and $100.0 \%$ for arginine and ascorbic \\ acid, respectively. Robustness was confirmed through factorial analysis $2^{2}$ ( $\mathrm{pH}$ and mobile phase flow rate as factors).
}

Keywords: Arginine, Ascorbic Acid, HPLC-UV, Tandem Columns, Vitamin C.

\section{Introduction}

L-arginine is a basic and hydrophilic amino acid classified as a conditionally essential amino acid and in humans is synthesized from citrulline (1). Arginine (ARG) plays an important role in protein synthesis and increase muscle endurance by delaying the occurrence of peripheral fatigue. ARG is the immediate precursor of nitric oxide (NO), urea, ornithine and agmatine and is necessary for the synthesis of creatine. As a precursor of $\mathrm{NO}$, arginine is used in many conditions where vasodilatation is required. It can also be used for the synthesis of polyamines (mainly through ornithine and to a lesser degree through agmatine, citrulline, and glutamate). Moreover, it is a precursor of proline and hydroxyproline, which are substances necessary for the synthesis of connective tissue $(2,3)$.
Ascorbic acid (AA) is a water soluble vitamin essential to humans. It is part of a group of chemicals complex necessary for the proper functioning of the body and its deficiency may be caused by an unbalanced diet. AA is important in metabolic processes such as synthesis of collagen, so vital for the repair and healing of connective tissue (4), and synthesis of norepinephrine (5) and steroids (6). In addition, it acts on the immune system and also as an antioxidant neutralizing free radicals and oxidants (7).

Analysis of ARG by reverse phase (RP) HPLC is commonly carried out by pre-column derivatization. This process is commonly used to reduce ARG polarity, improving the interaction with the RP column, and also increases the wavelength of detection. Studies employing o-phthaldialdehyde $(8,9)$ and phenyl 
isothiocyanate (10) for derivatization showed good results for analysis of ARG and metabolites. The sensitivity and selectivity of the mass detector were explored for the direct analysis of ARG and metabolites $(11,12,13)$. Few studies are described with direct analysis of arginine by HPLC-UV detection. In this context can be cited the separation of arginine, ibuprofen and its impurities with detection at $264 \mathrm{~nm}$ (with bandwidth of $100 \mathrm{~nm}$ to achieve the detection of ARG at wavelength around 210 $\mathrm{nm})$ (14). HPLC methods for AA employing electrochemical $(15,16)$ and UV $(17,18)$ detection are described for synthetic and biological samples.

Multidimensional chromatography employs two columns in sequence with different chromatographic selectivities. HPLC multidimensional methods are used to increase the resolution between substances in analysis of complex mixtures. Its advantageous is the direct analysis, in isocratic mode, of samples which commonly needed to be derivatized or require gradient system $(19,20)$.

The combination of arginine and ascorbic acid in effervescent tablets is indicated for cicatrization, as antioxidant, to improve the immune system and in restrictive or inadequate diets, when there is vitamin $\mathrm{C}$ deficiency. In our searches, we have found no method for quantifying arginine and ascorbic acid in pharmaceutical formulations. The present work aims to develop and validate a direct and fast multidimensional HPLC-UV method for determination of ARG and AA in effervescent tablets.

\section{Experimental}

AA standard was purchased from MBN Chemicals Ltd. ${ }^{\circledR}$ with purity of $99.81 \%$ and arginine aspartate standard from Zhejiang Medicines and Health Products Imp. Ex ${ }^{\circledR}$ with purity of $99.23 \%$. The concentration of arginine aspartate in the standard solutions was multiplied by the factor 0.567 to obtain the concentration of ARG. This factor was calculated by the ratio of ARG molecular weight $\left(174.2 \mathrm{~g}^{\mathrm{mol}}{ }^{-1}\right)$ by arginine aspartate (307.3 g.mol $\left.{ }^{-1}\right)$. Sodium phosphate dibasic anhydrous $\left(\right.$ Bold $\left.^{\circledR}\right)$, phosphoric acid $\left(\operatorname{Vetec}^{\circledR}\right)$
EDTA $\left(\right.$ Vetec $\left.^{\circledR}\right)$ and ultra-purified water from purification unit $\left(\mathrm{RF}\right.$ Easypure $\left.{ }^{\circledR}\right)$. Biofor $\mathrm{C}^{\circledR}$ effervescent tablets containing $1.0 \mathrm{~g}$ of ascorbic acid, $1.0 \mathrm{~g}$ of arginine aspartate and as inactive ingredients: citric acid, flavor solid with guarana açai, aspartame, sodium bicarbonate, colloidal silicon dioxide, colorant yellow, maltodextrin and mineral oil.

Chromatographic system consisted of a HPLC Merck Hitachi - Lachrom ${ }^{\circledR}$, diode array detector and HSM software Multi-Manager ${ }^{\circledR}$. Columns ACE ${ }^{\circledR}$ RP-18 (250 mm x 4 mm, $\left.5 \mu \mathrm{m}\right)$ and Spherisorb ${ }^{\circledR}$ cyanopropyl $(250 \mathrm{~mm} \times 4.6$ $\mathrm{mm}, 5 \mu \mathrm{m})$. Sample filtration through Millex Millipore ${ }^{\circledR}$ membrane (nylon, $0.45 \mu \mathrm{m}$ ).

\section{Sample Preparation}

All samples (ARG and AA) were dissolved and diluted with sodium phosphate dibasic 10 $\mathrm{mM}$ adjusted to $\mathrm{pH} 3.4$ with phosphoric acid and EDTA $0.005 \%$, diluent solution. EDTA was added to chelate metal ions and minimize the degradation of ascorbic acid in solution. The volumetric flasks were protected from light with aluminum foil to prevent degradation of ascorbic acid.

The standard stock solutions (SSS) were prepared by weighing $50 \mathrm{mg}$ of arginine aspartate, or $50 \mathrm{mg}$ of AA in $25 \mathrm{~mL}$ volumetric flask, diluting to obtain concentrations of 1.15 and $2.00 \mathrm{mg} \cdot \mathrm{mL}^{-1}$ for arginine and ascorbic acid, respectively. From these SSS were made dilutions to obtain the concentrations for validation test.

\section{Analytical Method Development}

Variations in chromatographic conditions including composition (acetonitrile, methanol and aqueous phases), $\mathrm{pH}(2.5-7.0)$ and flow rate $\left(0.6-1.2 \mathrm{~mL} \cdot \mathrm{min}^{-1}\right)$ of the mobile phase, and different columns (C18 and Cyanopropyl) were carried out to best fit the quantification of ARG and AA. 


\section{Validation Tests}

The chromatographic conditions employed for the quantification of $A R G$ and $A A$ are described in Table 1. The validation process used the ICH guides as a reference (21).

\begin{tabular}{|c|c|}
\hline \multicolumn{2}{|l|}{ HPLC } \\
\hline Variables & Description \\
\hline Mobile Phase & $10 \mathrm{mM}$ phosphate buffer $\mathrm{pH} 3.4$ \\
\hline Column & $\mathrm{ACE}^{\circledR} \mathrm{C} 18(250 \times 4 \mathrm{~mm}, 5 \mu \mathrm{m})$ and Spherisorb ${ }^{\circledR}$ \\
\hline Sequence & ciano-propil - 5CN (250 x $4.6 \mathrm{~mm}, 5 \mu \mathrm{m})$ \\
\hline $\begin{array}{l}\text { Injection } \\
\text { Volume }\end{array}$ & $20 \mu \mathrm{L}$ \\
\hline Flow rate & $1.0 \mathrm{~mL} / \mathrm{min}$ \\
\hline $\begin{array}{l}\text { Oven } \\
\text { Temperature }\end{array}$ & $30^{\circ} \mathrm{C}$ \\
\hline Detection & 205 nm (bandwidth 8 nm) \\
\hline $\begin{array}{l}\text { Run time } \\
\text { analysis }\end{array}$ & $7.5 \mathrm{~min}$ \\
\hline
\end{tabular}

\section{Specificity}

Chromatograms from tablet samples (at concentration of $100 \%$ ) were compared with placebo solution. Placebo solution was prepared by weighing a mixture of excipients of the effervescent tablets (anhydrous citric acid, baking soda, aspartame, maltodextrin, colloidal silicon dioxide, mineral oil, fragrance and dye) in volumetric flask of $25 \mathrm{~mL}$ using diluent as solvent. This solution was diluted to obtain placebo solution similar to those observed in the effervescent tablets.

For peak purity analysis, spectra in the range of 200-300 nm were recorded at a frequency of $0.5 \mathrm{~Hz}$ and noise set from $0.2-1.0 \mathrm{~min}$. No detected impurity was considered when the peak purity index was greater than 0.995 and the threshold curve did not intercept the similarity curve.

\section{Linearity}

Linearity of the method was demonstrated through the construction of curves in the range of $60-140 \%$ (140-320 and 240-560 $\mu \mathrm{g} \cdot \mathrm{mL}^{-1}$ for ARG and AA, respectively). For each curve were prepared five different concentrations $(60$, $80,100,120$ and $140 \%$ ), each one in triplicate in a total of 15 points (peak area vs concentration) per curve.

\section{Precision}

The method precision was evaluated by, repeatability and intermediate precision. Repeatability was determined by seven determinations at $100 \%$ of test concentration (230 and $400 \mu \mathrm{g} \cdot \mathrm{mL}^{-1}$ for ARG and AA, respectively) in duplicate. The test solutions were prepared from the triturated effervescent tablets which were weighted and diluted to working concentration. For each day of repeatability were prepared two standard solutions containing the drugs at a concentration of $100 \%$. The intermediate precision was determined by analyzing the repeatability of the method on different days.

\section{Accuracy}

Solutions containing ARG and AA contaminated with placebo were prepared to access method accuracy. Five concentrations were used, covering the range of the test $(60$, 80, 100, 120 and 140\%) for both drugs (ARG and AA). Each concentration was performed in duplicate. For calculation of recovery two standards containing only ARG and AA were prepared at $100 \%$ of test concentration.

\section{Robustness}

Robustness was evaluated by deliberate variations in $\mathrm{pH}$ and flow of mobile phase. The effect of factors ( $\mathrm{pH}$ and flow) in the quantification of drugs and the chromatographic parameters (resolution, peak asymmetry, retention time and column efficiency) were evaluated by factorial design $2^{2}$. Flow rate levels tested were 0.90 and 1.05 $\mathrm{mL} \cdot \mathrm{min}^{-1}$, and $\mathrm{pH} 3.2$ and 3.6. Analysis on the nominal level of the method $(\mathrm{pH} 3.4$ and flow 
of $1.00 \mathrm{~mL} \cdot \mathrm{min}^{-1}$ ) was performed to compare the results.

\section{Results and Discussion}

To obtain a chromatographic method for quantification of ARG and AA initially was tested reversed phase C18 columns (RP18), commonly used in drug analysis. ARG is positively charged $(\mathrm{pKa}=13.2)$ across the $\mathrm{pH}$ range commonly used in HPLC ( $\mathrm{pH} 2.0-8.5)$ which reduces the affinity of the drug by RP18 column. To increase the affinity of ARG was added sodium dodecyl sulfate (SDS $0.2 \%$ ) on mobile phase as ion pair. This approach increase the retention time of ARG, but was not succeeded in separating the drugs under analysis (Figure 1.a).

Figure 1. Chromatograms of arginine (ARG) and ascorbic acid (AA) obtained during the method development. a) Phase reverse C18 (RP18) column using SDS as ion pair; b) Cyanopropyl column using pentane sulfonate as ion pair.
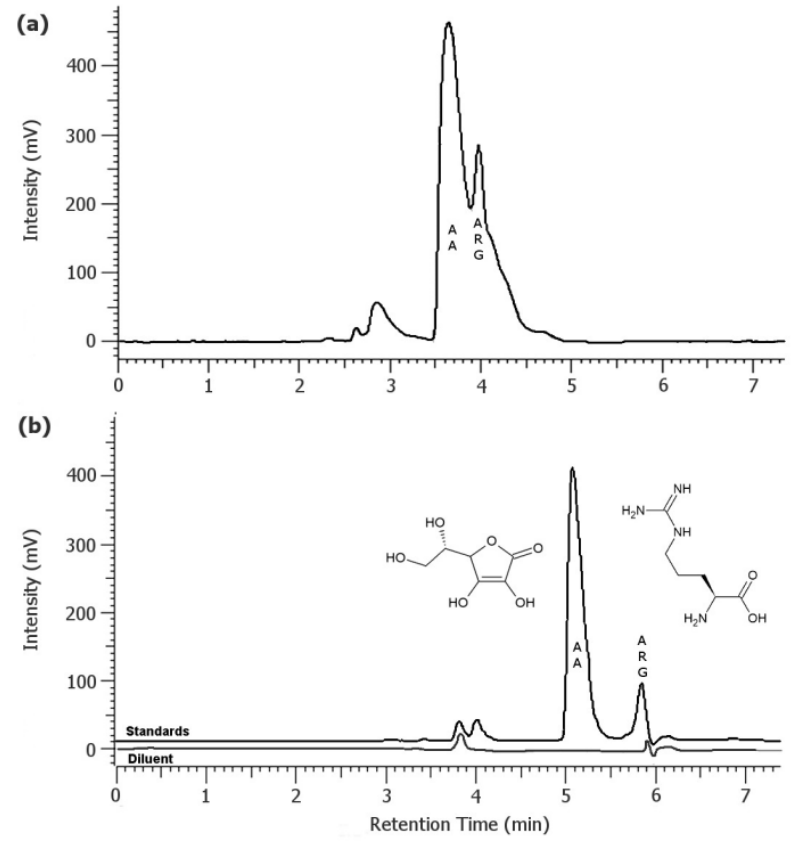

Due to the high polarity and water solubility of AA and ARG, were carried out assay with polar cyanopropyl column using phosphate buffer $\mathrm{pH} 3.4$ as mobile phase. Pentane sulfonate $(0.2 \%)$ was added to mobile phase, as ion pair, resulting in satisfactory resolution between the drugs and placebo (Figure 1.b). However, the diluent showed relevant signal at the same retention time of ARG. The influence of the diluent under these conditions was confirmed with peak purity value $<0.9$ and high value of the intercept $(8.5 \%)$ in a study of linearity with the ARG standard (Figure 2). The values of percentage intercept calculated by equation 1 must be lower than the specification established for precision (relative standard deviation - RSD $<2.0 \%$, in this case), demonstrating that the method variation/error explain the intercept dimension obtained in the linearity test (22).

$\%$ Intercept $=\frac{a}{b \times \bar{X}} \quad$ Equation 1

Where $a$ is the intercept; $b$ is the slope; $\bar{X}$ is the mean concentration.

Figure 2. Linearity plot of arginine using different columns (CN - cyanopropyl column, and multidimensional chromatography - RP18 + cyanopropyl columns in sequence). In bold the results of intercept percentage calculated by equation 1 . $\mathrm{CN}$ data were normalized dividing it by the sum of multidimensional chromatography area.

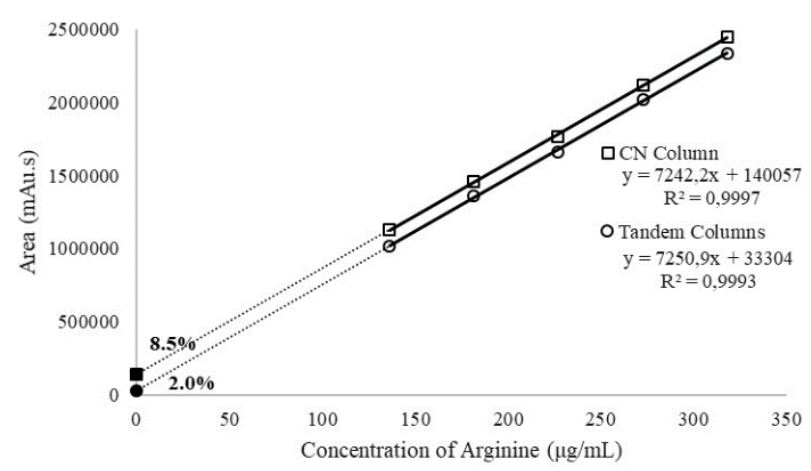

Satisfactory results for the resolution of the drugs peaks, placebo and diluent were obtained using the columns RP18 and cyanopropyl in sequence (multidimensional chromatography) (Figure 3). Using this method there was no need of adding substances to ion pairing. Under these conditions it was possible to validate the method for quantification of ARG and AA as demonstrated by the results and discussions described below.

\section{Specificity}

In general, the use of wavelengths below 210 $\mathrm{nm}$ is avoided, basically for two reasons: the 
emission of the deuterium lamp is lower in this band (signal/noise ratio is high and sensitivity low) and many interferers absorb in this region (potential specificity problem). At $205 \mathrm{~nm}$ ARG and AA (maximum and minimum wavelength, respectively) have similar absorptivities. As the working concentrations were not close to the limit of quantification and the placebo did not interfere with the analysis (as will prove the results of validation), the wavelength of $205 \mathrm{~nm}$ was selected for the ARG and AA quantifications.

There was no peak detected for placebo at the retention time corresponding to the chromatographic peaks of ARG and AA (Figure 3). Peak purity analysis does not detected impurities on the peaks of ARG and AA and the peak purity index was higher than 0.999 for both drugs. Retention times of ARG and AA were 6.30 and 6.95 min, respectively. The inversion in the order of elution of the drugs in the multidimensional chromatography method with respect to the methods of Figure 1 can be justified by the absence of ionic pair agent that alters the interaction of drugs with the columns.

Figure 3. Chromatograms of the Biofor $\mathrm{C}$ effervescent tablets and placebo at 205 $\mathrm{nm}$ with the columns RP-18 and cyanopropyl in sequence (multidimensional chromatography). Concentrations of 230 and $400 \mu \mathrm{g} \cdot \mathrm{mL}^{-1}$ for arginine (ARG) and ascorbic acid (AA), respectively.

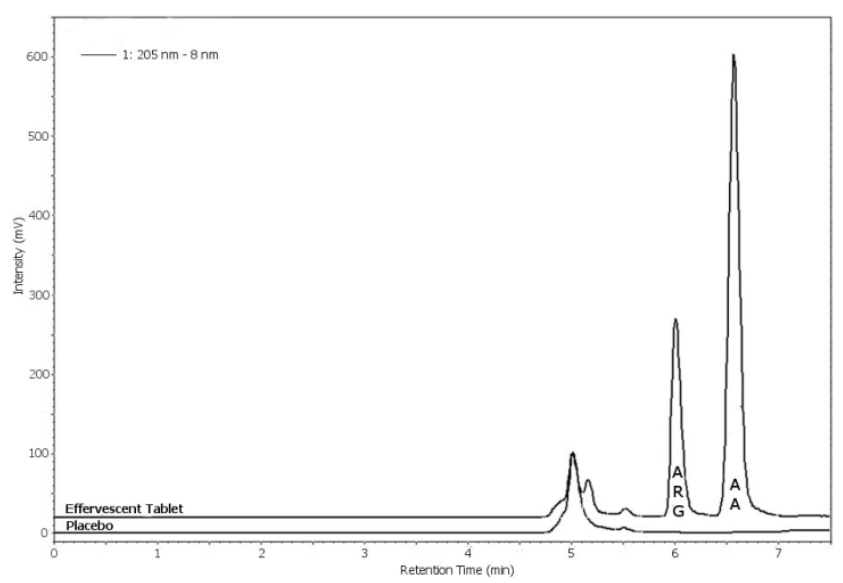

\section{Linearity}

The linear regression lines were obtained plotting the peak area at $205 \mathrm{~nm}$ (in mAu.s) versus the concentration of ARG or AA (in $\left.\mu \mathrm{g} . \mathrm{mL}^{-1}\right)$. The summary of results are in Table 2. The higher slope obtained with the results of AA compared to ARG shows a greater sensitivity of the method for detection of AA. The coefficients of determination $\left(r^{2}\right)$ close to 1.00 show that virtually all the variation on the peak areas can be explained by variations in the concentrations of the drugs. The standardized residuals in the range of -2.0 to 2.0 shows that there were no outliers for peak area in the experimental data. Residual graphics showed normal distribution of results without the presence of trends, demonstrating that the model of first order, without transformation of data, is adequate to describe the relationship between peak area and concentration of the drugs. The ratio of the standard error of regression (SER) and the mean peak area obtained by the linear regression equation can be considered a measure of dispersion of the results of linearity (Equation 2), and comparable to the calculated RSD of the precision results. The low values of $\mathrm{RSD}_{\text {reg }}$ show that the method has adequate precision and were compatible with the technique and sample (tablets) analyzed (22)

$R S D_{\text {reg }}=\frac{S E R}{b \times \bar{X}} \times 100 \% \quad$ Equation 2

Where: $\mathrm{RSD}_{\text {reg }}=$ relative standard deviation of the regression in \%; SER $=$ standard error of regression, $\mathrm{b}=$ the regression slope, $\bar{X}=$ average concentration of the samples in the calibration curve.

Table 2. Summary of linearity results.

\begin{tabular}{lcc}
\hline Linearity & Arginine & Ascorbic Acid \\
\hline $\begin{array}{l}\text { Concentration Range } \\
(\mu \mathrm{g} / \mathrm{mL})\end{array}$ & $140-320$ & $240-560$ \\
Equation & $y=7251 \mathrm{x}+33304$ & $\mathrm{y}=10903 \mathrm{x}+83049$ \\
Determination & 0.9993 & 0.9998 \\
Coefficient ( $\left.\mathrm{r}^{2}\right)$ & & \\
Standadized & & \\
Residuals (Extreme & & $-1.20,+1.13$ \\
Values) & & \\
Residuals Plot & No tendency & No tendency \\
Regression Precision & $1.44,+1.33$ & $0.5 \%$ \\
Percentage Intercept & $2.0 \%$ & \\
\end{tabular}




\section{Precision}

There is additive variance between the levels of precision and the highest variability is expected for the intermediate precision which includes the variations of system precision and repeatability. For samples at the same level of concentration is possible to calculate the system precision, from injections in duplicate, using Equation 3 (23).

$R S D_{I n j}=\frac{\sqrt{\frac{\sum\left(x_{i 1}-x_{i 2}\right)^{2}}{2 k}}}{\bar{x}} \times 100 \% \quad$ Equation 3

Where: $\mathrm{RSD}_{\text {Inj }}$ is the HPLC system precision, in $\% ; \mathrm{x}_{\mathrm{i} 1}$ and $\mathrm{x}_{\mathrm{i} 2}$ are the peak areas of different injections of the sample $\mathrm{i} ; \mathrm{k}$ is the number of samples; $\bar{x}$ is the average peak area of the samples.

Repeatability was evaluated by calculating the RSD (RSD $\left.{ }_{\text {Rep }}\right)$ from the results of different samples in each day of precision assay. The intermediate precision was obtained by measuring the variability $\left(\mathrm{RSD}_{\mathrm{Int}}\right)$ of pooled results from different days of precision. Table 3 summarizes the results. Low values of RSD $(<$ $2.0 \%$ ) evaluated at all levels show that the method is precise.

During the precision assay has been verified that the sample solutions containing the drugs were stable for at least $12 \mathrm{~h}$.

Table 3. Summary of results from different levels of precision for effervescent tablets.

\begin{tabular}{|c|c|c|c|c|}
\hline \multirow[b]{2}{*}{ Precision } & \multicolumn{2}{|c|}{ Arginine } & \multicolumn{2}{|c|}{ Ascorbic acid } \\
\hline & Day 1 & Day 2 & Day 1 & Day 2 \\
\hline $\begin{array}{c}\text { Injection precision }-\mathbf{R S D}_{\text {Inj }} \\
(\%)\end{array}$ & 0.41 & 0.54 & 0.43 & 0.36 \\
\hline Repeatability - RSD Rep $_{(\%)}$ & 1.64 & 1.41 & 1.04 & 1.12 \\
\hline $\begin{array}{c}\text { Intermediate precision - } \\
\text { RSD Int }_{\text {(\%) and (Dose) }}\end{array}$ & \multicolumn{2}{|c|}{$1.57(102.4 \%)$} & \multicolumn{2}{|c|}{$1.37(97.0 \%)$} \\
\hline
\end{tabular}

\section{Accuracy}

Recoveries of the drugs in the samples contaminated with placebo were $99.5 \%$ and $100.0 \%$ for $\mathrm{ARG}$ and AA, respectively. Variability of results was low with values of RSD for the ten samples, equal to $1.82 \%$ and $1.11 \%$ for ARG and AA, respectively. These results confirm the specificity, accuracy and precision of the analytical method proposed.

\section{Robustness}

An analytical method for use in routine should be able to withstand small variations without changing significantly the quantification of drugs. The proposed method is robust to variations on the factors $\mathrm{pH}$ and flow showing low variability (Table 4).

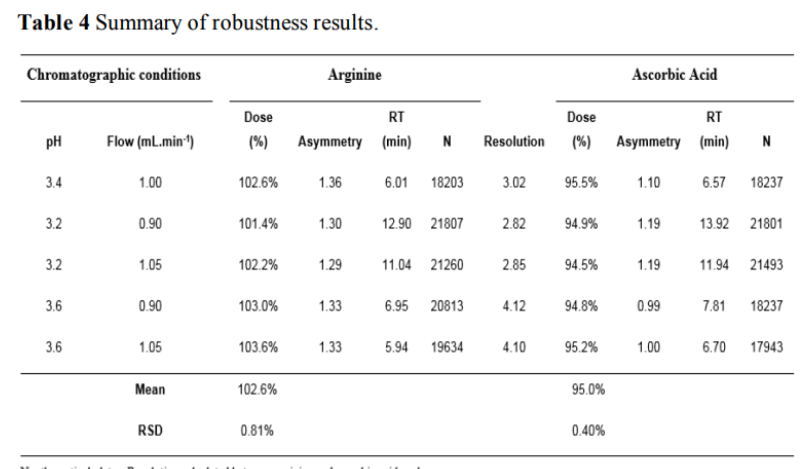

The transfer of analytical methods between laboratories often requires adaptations to adjust the chromatographic parameters (resolution, asymmetry, retention time). Thus, the analysis of the results of deliberate variations in method indicates that the $\mathrm{pH} 3.6$ improves the resolution between peaks; the retention time increases with $\mathrm{pH} 3.2$; the asymmetry of the peak of ARG is better at $\mathrm{pH} 3.2$, while AA is at $\mathrm{pH}$ 3.6. The analysis with similar columns under the same conditions that was proposed in this study showed low resolution between ARG and AA. This problem was easily solved by reducing the flow to $0.8 \mathrm{~mL} \cdot \mathrm{min}^{-1}$ and increasing $\mathrm{pH}$ to 3.6. 


\section{Conclusions}

The use of multidimensional chromatography was effective to separate and quantify ARG and AA from effervescent tablets and there is no need for pre-column derivatization. The intercept from linear regression was able to detect a quantitative influence of the diluent in the analysis of ARG during the development phase of the HPLC method leading us to the use of multidimensional chromatography. Satisfactory results for specificity, linearity, precision, accuracy and robustness validate the method for analysis of effervescent tablets containing ARG and AA by multidimensional HPLC-UV.

\section{Acknowledgements}

The authors would like to thank Vitamed Laboratory for kindly supplying chromatographic columns and reference materials.

\section{Conflict of Interest}

The authors declare no conflicts of interest.

\section{References}

1. Bahri S, Zerrouk N, Aussel C, Moinard C, Crenn P, Curis E, et al. Citrulline: from metabolism to therapeutic use. Nutrition. 2013; 29(3): p. 479-84.

2. Böger RH. The pharmacodynamics of Larginine. Altern Ther Health Med. 2014; 20(3): p. 48-54.

3. Lorin J, Zeller M, Guilland JC, Cottin Y, Vergely C, Rochette L. Arginine and nitric oxide synthase: regulatory mechanisms and cardiovascular aspects. Mol Nutr Food Res. 2014; 58(1): p. 101-16.

4. Kishimoto Y, Saito N, Kurita K, Shimokado K, Maruyama N, Ishigami A. Ascorbic acid enhances the expression of type 1 and type 4 collagen and SVCT 2 in cultured human skin fibroblasts. Biochem Biophys Res Commun. 2013; 430(2): p. 579-84.

5. May JM, Qu ZC, Nazarewicz R, Dikalov S. Ascorbic acid efficiently enhances neuronal synthesis of norepinephrine from dopamine. Brain Res Bull. 2013; 90: p. 3542.

6. Lodhi GM, Latif R, Hussain MM, Naveed AK, Aslam M. Effect of ascorbic acid and alpha tocopherol supplementation on acute restraint stress induced changes in testosterone, corticosterone and nor epinephrine levels in male Sprague Dawley rats. J Ayub Med Coll Abbottabad. 2014; 26(1): p. 7-11.

7. Chang Z, Huo L, Li P, Wu Y, Zhang P. Ascorbic acid provides protection for human chondrocytes against oxidative stress. Mol Med Rep. 2015; 12(5): p. 7086-92.

8. Zhang W, Kaye DM. Simultaneous determination of arginine and seven metabolites in plasma by reversed-phase liquid chromatography with a timecontrolled ortho-phthaldialdehyde precolumn derivatization. Anal. Biochem. 2004; 326(1): p. 87-92.

9. Markowski P, Baranowska I, Baranowski J. Simultaneous determination of 1arginine and 12 molecules participating in its metabolic cycle by gradient RP-HPLC method: Application to human urine samples. Anal. Chim. Acta. 2007; 605(2): p. 205-17.

10. Mao H, Wei W, Xiong W, Lu Y, Chen B,

0 Liu Z. Simultaneous determination of 1citrulline and 1-arginine in plasma by high performance liquid chromatography. Clin. Biochem. 2010; 43(13-14): p. 1141-7. 
11. Alkaitis MS, Nardone G, Chertow JH, Ackerman HC. Resolution and quantification of arginine, monomethylarginine, asymmetric, dimethylarginine, and symmetric, dimethylarginine in plasma using HPLC with internal calibration. Biomedical Chromatography. 2016; 30: p. 294-300.

12. Martens-Lobenhoffer J, Bode-Böger SM. Mass spectrometric quantification of $\mathrm{L}$ arginine and its pathway related substances in biofluids: The road to maturity. Journal of Chromatography B. 2014; 964: p. 89-102.

13. Servillo L, Giovane A, D'Onofrio N, Casale R, Cautela D, Castaldo D, et al. Determination of Homoarginine, Arginine, NMMA, ADMA, and SDMA in Biological Samples by HPLC-ESI-Mass Spectrometry. International Journal of Molecular Sciences. 2013; 14(10): p. 20131-20138.

14. Huidobro AL, Rupérez FJ, Barbas C. Tandem column for the simultaneous determination of arginine, ibuprofen and related impurities by liquid chromatography. J Chromatogr. A. 2006; 1119: p. 238.

15. Khan MI, Iqbal Z, Khan A. Simultaneous determination of ascorbic acid, aminothiols, and methionine in biological matrices using ion-pairing RP-HPLC coupled with electrochemical detector. Methods Mol Biol. 2015; 1208: p. 201-20.

16. Li X, Franke AA. Fast HPLC-ECD analysis of ascorbic acid, dehydroascorbic acid and uric acid. J Chromatogr B Analyt Technol Biomed Life Sci. 2009; 877(10): p. 853-6.

17. Ibrahim F, El-Enany N, El-Shaheny RN, Mikhail IE. Development and Validation of a New HPLC Method for the
Simultaneous Determination of

Paracetamol, Ascorbic Acid, and Pseudoephedrine $\mathrm{HCl}$ in their Coformulated Tablets. Application to in vitro Dissolution Testing. Anal Sci. 2015; 31(9): p. 943-7.

18. Wang YH, Avonto C, Avula B, Wang M, Rua D, Khan IA. Quantitative Determination of $\alpha$-Arbutin, $\beta$-Arbutin, Kojic Acid, Nicotinamide, Hydroquinone, Resorcinol, 4-Methoxyphenol, 4Ethoxyphenol, and Ascorbic Acid from Skin Whitening Products by HPLC-UV. J AOAC Int. 2015; 98(1): p. 5-12.

19. Chalcraft KR, McCarry BE. Tandem LC columns for the simultaneous retention of polar and nonpolar molecules in comprehensive metabolomics analysis. Journal of Separation Science. 2013; 36: p. 3478-85.

20. Link AJ WM. Analysis of protein composition using multidimensional chromatography and mass spectrometry. Curr Protoc Protein Sci. 2014; 78: p. 1-25.

21. ICH Harmonised Tripartite Guideline. Validation of analytical procedures: text and methodology Q2(R1); 2005 [cited 2017 december 22. Available from: http://www.ich.org/products/guidelines/q uality/quality-single/article/validation-ofanalytical-procedures-text-andmethodology.html.

22. Miron D, Lange A, Zimmer AR, Mayorga $P$, Schapoval EES. HPLC-DAD for the determination of three different classes of antifungals: method characterization, statistical approach, and application to a permeation study. Biomed. Chromatogr. 2014; 28: p. 1728-37.

23. Ermer, J. Validation in pharmaceutical analysis. Part I: An integrated approach. 
Journal of Pharmaceutical and Biomedical

Analysis. 2001; 24: p. 755-767. 